\title{
Comparative Study of the Intersection of Engineering Identify and Black Identity of African-American Engineering Students at a PWI and an HBCU
}

\section{Dr. Lesley M. Berhan, University of Toledo}

Lesley Berhan is currently the Interim Assistant Dean of Diversity, Inclusion, and Community Engagement for the College of Engineering and an Associate Professor in the department of Mechanical, Industrial, and Manufacturing Engineering at The University of Toledo. Her research interests are in the areas of composites and fibrous materials and engineering education. She received her B.Sc. in Civil Engineering from the University of the West Indies in St. Augustine, Trinidad, her M.S. in Civil Engineering from the Massachusetts Institute of Technology, and her Ph.D. in Mechanical Engineering from the University of Michigan, Ann Arbor. She joined the faculty at the University of Toledo in 2004. As the Assistant Dean of Diversity, Inclusion, and Community Engagement, she leads the development and execution of initiatives and programs to facilitate the recruitment, retention, and success of women, students from underrepresented groups and first generation students. These duties are well aligned with her current research interests and external funding in engineering education

\section{Dr. Revathy Kumar, University of Toledo}

Ph.D. in Education and Psychology from the Combined Program in Education and Psychology, University of Michigan. At the graduate level, she teaches courses in Adolescent Development, Motivational Theory and Application, Cultural Perspectives in Learning and Development, and Self and Identity. Her research focuses on social and cultural processes involved in constructing a sense of self and identity among adolescents in culturally diverse societies. Of particular interest are the role of teachers, teacher-education programs, schools, communities, and families in facilitating minority and immigrant adolescents' development, learning, and motivation. Her work is published in Journal of Teacher Education, Journal of Educational Psychology, Journal of Research on Adolescence, Contemporary Educational Psychology, and Cultural Diversity and Ethnic Minority Psychology. She received a Spencer Foundation Grant in 2007 to examine academic prospects, interpersonal relationships, and social well-being of students in school districts with a high concentration of students of Arab and Chaldean origins. Recently, she received internal grants from the University of Toledo to conduct mindfulness intervention projects with elementary school students and preservice teachers. She is also the recipient of the Fulbright Specialist Fellowship to pursue her interest in culture, mindfulness, and motivation in cross-cultural and international contexts.

\section{Ms. Marjory A. Goodloe, University of Toledo}

Marjory Goodloe is a doctoral student at the University of Toledo with expertise in educational policy and educational leadership. An acclaimed community activist and writer, Marjory is dedicated to improving the lives of youth in foster care; as such, she has spent nearly a decade developing programs geared toward improving the educational outcomes of youth in foster care. Her passion for education reform led her to pursue a doctorate in Educational Theory \& Social Foundations with a minor in Educational Administration Supervision.

\section{Mr. Jimmie Jones, University of Toledo}

Jimmie Jones is a doctoral student in the Judith Herb College of Education's Educational Psychology program at the University of Toledo. His research focus is concerned with understanding the ways in which culture and climate impact student's cognition, attitudes, behaviors, and outcomes. His population of interest is racial/ethnic minorities, with African American student experiences as a focal point.

\section{Dr. Aaron Lee Adams, Alabama A\&M University}

Aaron Adams is an assistant professor in the Department of Mechanical and Civil Engineering at Alabama A \& M University. Before pursuing graduate studies, he worked at the National Academy of Engineering \& Ford Motor Company as a product design engineer focusing on Minority STEM education and environmental policies. His research interests include nuclear radiation detection and thermal electric material 
development. He also works with the Center for Entrepreneurship Innovation and Economic Development to encourage African American students, and underrepresented groups in developing business innovation and ideas. 


\section{Comparative Study of the Intersection of Engineering Identify and Black Identity of African American Engineering Students at a PWI and an HBCU}

This interdisciplinary, inter-institutional research initiation project is motivated by the need to develop practical strategies for broadening the participation of African American students in engineering. The central objective of the project is to conduct a comparative study of the factors affecting the success and pathways to engineering careers of African American students at a Predominantly White Institution (PWI), the University of Toledo, and a Historically Black University (Alabama Agricultural and Mechanical University). Through this research we hope to gain insight into the factors affecting the social and academic well-being of students at PWIs and HBCUs from a psychological and anthropological perspective.

For students from underrepresented groups in STEM at both HBCUs and PWIs it is generally recognized that social capital in the form of familial, peer and mentor support is critical to persistence in their major field of study. However, the role that embedded networks within student groups in general, and minority engineering affinity groups in particular, play in engineering students' identity formation and academic success is not well understood. It is also not clear how other factors including institutional support and the attitudes and beliefs of faculty and staff toward underrepresented minority students affect the ability of these students to integrate into the social and academic systems at their institutions and how these factors influence the formation and development of their identities as engineers. Here we report on the role of membership in organizations for underrepresented minority engineering students such as the National Society of Black Engineers (NSBE) in contributing to the interlinking of personal and professional identities, and to the career pathways of African American students enrolled in PWI and HBCU, respectively.

Theoretical Perspectives: Social Identity and Ecological Systems Theories

Social identity theory $[1,2]$ emphasizes the distinction between relevant and meaningful social groups and an individual's commitment to and identification with specific social groups. The theory examines the psychological processes associated with identity negotiations based on ingroup affiliation and social categorization of self and others. Specifically, social identity negotiation is a social phenomenon that becomes subjectively meaningful by defining an individual's place in the world, satisfying the need to belong.

Social identity is not singular; rather it is multi-faceted with the salience of any particular facet and the consonance among different facets dependent on social contexts and everyday life experiences [3, 4]. The Phenomenological Variant on Ecological Systems (PVEST) theory [5, 6] is an extension of Bronfenbrenner's [3] ecological systems model and integrates considerations of macro and micro-level developmental contexts giving due regard to the individual's developmental needs. PVEST suggests that humans are vulnerable, possessing both risk and protective factors which translate into normative and non-normative challenges and supports to inform developmental trajectories [7]. Thus PVEST integrates ecological systems theory with the phenomenological experience of the individual to understand how individuals interact with their contexts - distal and proximal - to forge unique developmental pathways. These frameworks enable us to examine the distinctive contextual features PWI and HBCU institutions and the role 
of organizations such as NSBE in integrating African American engineering students’ personal and professional identities and advancing their career.

Comparative research of African American students in PWI vs. HBCU (see Oucalt \& SkewesCox, [8] for review) suggests that the level of dissonance African American students experience and the ease with which they merge their professional and personal identities depends on the institutional context. Oucalt and Skewes-Cox [8] report that the social support networks for African-American students are stronger in HBCUs as compared to PWIs. According to Mendonza-Denton, Downey, Purdie, Davis, \& Pietrzak, [9] it is the salience of their minority status coupled with low expectations regarding their academic success from faculty and peers in PWIs that is detrimental to African American students' mental wellbeing, adjustment to the institution, and their academic performance. As well, Bonous-Hammarth and Boatsman [10] report that African-American students at HBCUs were more satisfied with their every-day experiences than their counterparts at PWIs. As Oucalt and Skewes-Cox [8] state, "most important elements in HBCUs' unique advantages are related to students 'experience with their human environment (p.344)." Lacking this advantage, African American engineering students' in PWIs require other places and spaces, such as membership in NSBE, where they have the opportunity to forge a strong professional identity while preserving a positive African-American identity.

Summary of Hypotheses

Based on the literature reviewed we hypothesize that:

1) HBCU institutions promote a stronger integration of racial and professional engineering identity than do PWI institutions.

2) Membership in professional organizations such as NSBE is beneficial African American engineering students in both institutions.

3) Membership in professional organizations such as NSBE will be significantly more beneficial for African American in PWIs than HBCUs.

Sample and Sample Selection

Data in this study were from 11 focus group interviews conducted at a HBCU ( $\mathrm{n}=7$ on average) and a PWI ( $\mathrm{n}=4$, on average). African American undergraduate engineering students in the HBCU institution were selected utilizing stratified random sampling. The sample selection procedure at the PWI institution was constrained due to the relative small number of African American students in the undergraduate engineering programs. It is important to note that while the PWI institution included both engineering technology (ET) and engineering programs (EN), the HBCU institution offered only engineering majors and did not include engineering technology. Therefore, sample selection at the PWI included a further level of stratification by program.

Interview Protocol and Interview Process

The focus group protocol was constructed from protocols used in previous research on prejudice and discrimination among college, middle, and high school minority students that included 
African American, Latinx, and Arab American students [11]. Open-ended questions provided interviewees ample opportunities for frank discussion about issues and concerns crucial to their lives in and outside school [12]. The protocol included questions regarding perceptions of the campus and engineering college context including faculty's cultural sensitivity and culturally responsive teaching, perceptions of stereotyping and discrimination in societal and institutional contexts and their feelings of inclusion/exclusion and dissonance on campus and within the professional engineering community.

Focus group facilitators were of African or African American descent in order to build rapport with participants. Students received a twenty-five dollar (\$25) gift card for their participation. Focus group interviews were recorded and transcribed and later coded by an interdisciplinary team consisting of six individuals.

Coding and Analysis

Interviews were audiotaped and transcribed verbatim. Transcripts were then coded and analyzed with the assistance of QSR NVivo 11 software. Four analysts from diverse ethnic backgrounds coded the data. We utilized a qualitative phenomenological approach to conduct a comparative analysis of the experiences of African American Engineering students in the two types of institutions. A phenomenological approach describes what research participants have experienced, how they experienced it, and the meaning they associate to their experiences [13]. Students shared their experiences and their perceptions of their institutions and their views on issues related to race, ethnicity, identity and career aspirations.

Initially, we developed a priori codes/ categories in accordance with the literature review. Next, each of the four researchers read the interviews to get a feel for interviewees' experiences in the two contexts - HBCU and PWI. Then each researcher conducted a deeper analysis of the data and pulled out emerging themes from the interviews. We discussed the emerging themes, compared them to the a priori codes. We arrived at a consensus regarding the thematic categories (e.g., awareness of prejudice and discrimination, collective experience of prejudice and discrimination, personal experience of prejudice and discrimination, sense of belonging to the institution, sense of professional belonging) through dialogue and discussion. To the extent possible, we attempted to describe what the participants were stating without inserting our interpretations. This enabled us to objectively organize the data and create codes that we determined authentically reflected participants expressed experiences.

Results

Results reported here are preliminary as we are still in the data collection phase of the study. Student voices, and hence the lived experiences of students from both institutions are included as much as possible to ensure accuracy in reporting.

Regarding the first hypothesis, results from the data show that while students from both institutions have positive racial identity, that identity is reflected in different ways. Students from the HBCU expressed their racial identity in terms of a cultural congruence between them and the HBCU which led them to feel an immediate relationship with the university. In their discussions, 
unlike the majority of PWI students, student narratives from the HBCU oftentimes compared their experiences to their firsthand knowledge or perceptions of what happens at PWIs versus HBCUs. For example, one student said:

"I feel like I am more in touch with my culture. As far as just the black culture. I have friends that go to PWIs and I am a little more, the word I would use is cultured, than them. At the PWI, they try more so to have to blend in, whereas at HBCUs, you learn how to be yourself when it's time to be yourself and when it is time to blend in, blend in. Versus at a predominately white institution, where you always have to blend in to be accepted in such and such field or at such and such place.”

Another student in a different focus group expressed similar thoughts, saying:

"It's a little different. Of course, the majority of students are black. Here on campus, we are the majority. At a PWI, it's more of the norm to conform to I guess the conditional American ways, and being able to blend in and act as such. Here at HBCUs, you are comfortable with your background, your ethnicity, and you don't always have to conform."

Students at the HBCU did not feel a need to assimilate into an academic culture they believed that already shared their own culture. Students' narratives at the PWI related to racial identity focused almost exclusively on race, racial pride, and fitting in at the institution. While these students' narratives suggest they are proud to be Black while attending a PWI, they were keenly aware of their minority status at the institution and their perceived subordinate role. For example, a student in one of the focus groups said:

"I am very much aware of my race on campus. A lot of times you need to double think what you're about to do because of your race. I am a tall black man, so I am already coming off as sort of being aggressive. Some things you need to make sure you don't say or do because people might rub it the wrong way. Everyone knows I am not aggressive. I have never been in a fight my entire life. I am a gentle giant. But people just see this big guy and he's black too, so you definitely have to be aware of your race.”

With regard to hypothesis 2, students from both institutions saw the value in professional organization membership. Students at the HBCU enthusiastically endorsed the importance of organizations such as NSBE in providing opportunities for professional networking. They also emphasized the role of NSBE in providing a sense of belonging to the engineering profession. Some engineering technology students at the PWI also recognized the value of NSBE in providing them professional opportunities. As one senior engineering technology student remarked, “That is how I got my internship at Chrysler. That is why I joined NSBE," and another chimed in:

"I felt like I wasn't really applying myself in college. I could be taking advantage of all these opportunities around me. So I joined NSBE and met some really cool people that I still talk to. My first year at nationals was really fun. I ended up getting a second internship from that. But the reason I joined was to increase my professional network and have more opportunities to have jobs.”

Contrary to expectations, we did not find strong support for hypothesis 3. Additional focus group 
and individual interviews currently being conducted at the PWI and HBCU may shed additional light on this issue.

\section{Discussion}

The study demonstrates that an understanding of the phenomenological contexts within which students, in this instance, African American engineering students negotiate their everyday life is essential [5]. This is illustrated in the comparative analyses of focus group interviews conducted at the two institutions. For example, while students from the HBCU discussed the advantages they accrued because of the cultural consonance between their community and university cultures; PWI students bemoaned the extent to which they experienced cultural dissonance. They manifested the negative affective and academic outcomes, namely, feelings of anger, hopelessness, lowered feelings of academic efficacy and concerns about their academic future associated with feelings of cultural dissonance [14]. This has important implications at PWI institutions. PWI institutions must develop culturally inclusive environments. These institutions need to institute cultural competency professional development programs that enable faculty to recognize their personal biases, and learn how to suspend judgements and behavioral responses that are often enacted unconsciously.

The results also demonstrate that faculty at HBCU were cognizant of societal stereotypes regarding African American engineers and therefore made explicit efforts to help students integrate their collective and professional identity. More importantly, African American faculty were role models for these students, demonstrating that African American students can develop a "relevant black personality" that allows them to "choose academic excellence yet still identify with African American culture” (p. 20, [15]).

While students in both institutions talked about the advantages of membership to professional organizations, it appears that this was particularly beneficial for African American students in the PWI institution. It probably helped to ameliorate, to some degree, the alienation they experienced in the university context. It provided these students the opportunity to explore their professional options and a safe space to consolidate their personal and professional identities and attain a sense of coherence.

\section{Acknowledgements}

Support for this research by the NSF Division of Engineering Education and Centers award number 1640553 is gratefully acknowledged.

[1] H. Tajfel, Human groups and social categories: Studies in social psychology. Cambridge, UK: Cambridge University Press, 1981.

[2] H. Tajfel and J. C. Turner, "The Social Identity Theory of Intergroup Behavior," in The psychology of intergroup relations S. Worchel and W. G. Austin, Eds. Chicago, IL: Nelson-Hall, 1986, pp. 7-24.

[3] U. Bronfenbrenner, The ecology of human development: Experiments by nature and design. Cambridge, MA: Harvard University Press, 1979. 
[4] G. M. Walton and S. J. Spencer, "Latent Ability: Grades and Test Scores Systematically Underestimate the Intellectual Ability of Negatively Stereotyped Students," Psychological Science, vol. 20, no. 9, pp. 1132-1139, 2009/09/01 2009.

[5] M. B. Spencer, "Social and cultural influences on school adjustment: The application of an identity-focused," Educational Psychologist, vol. 34, no. 1, pp. 43-57, 1999/01/01 1999.

[6] D. P. Swanson et al., "Psychosocial development in racially and ethnically diverse youth: Conceptual and methodological challenges in the 21st century," Development and Psychopathology, vol. 15, no. 3, pp. 743-771, 2003.

[7] M. B. Spencer, "American Identity: Impact of Youths' Differential Experiences in Society on Their Attachment to American Ideals," Applied Developmental Science, vol. 15, no. 2, pp. 61-69, 2011/04/19 2011.

[8] C. L. Outcalt and T. E. Skewes-Cox, "Involvement, Interaction, and Satisfaction: The Human Environment at HBCUs," The Review of Higher Education, vol. 25, no. 3, pp. 331-347, 2002.

[9] R. Mendoza-Denton, G. Downey, V. J. Purdie, A. Davis, and J. Pietrzak, "Sensitivity to statusbased rejection: Implications for African American students' college experience," Journal of Personality and Social Psychology, vol. 83, no. 4, pp. 896-918, 2002.

[10] M. Bonous-Hammarth and K. Boatsman, "Satisfaction guaranteed? Predicting academic and social outcomes for African American college students," presented at the Annual Conference of the American Educational Research Association, New York, NY, 1996.

[11] R. Kumar, W. Mckether, and M. Goodlow, "Retention and graduation of minority students: Institutional affordances and barriers," in Great Lakes Regional Student Success Conference: Putting It All Together: Campus Strategy for Access, Retention, and Completion, Detroit, MI, 2017.

[12] J. Kitzinger, "Qualitative research: Introducing focus groups," British Medical Journal, vol. 311, no. 7000, pp. 299-302, Jul 1995.

[13] C. E. Moustakas, Phenomenological research methods Thousand Oaks, CA: Sage Publications, 1994.

[14] R. Arunkumar, C. Midgley, and T. Urdan, "Perceiving high or low home-school dissonance: Longitudinal effects on adolescent emotional and academic well-being," Journal of Research on Adolescence, vol. 9, no. 4, pp. 441-466, 1999.

[15] Ladson-Billings, The dreamkeepers: Successful teachers of African American children 2nd ed. San Francisco, CA: Jossey-Bass., 2009. 